\title{
Colchicine induced polyploidy in
coriander (Coriandrum sativum L.)
}

\author{
Rakesh Purbiya**, Rakesh Chandra Verma', Preeti Dass² and \\ Chhatar Sing Chouhan ${ }^{3}$
}

${ }^{1}$ School of Studies in Botany, Vikram University, Ujjain-456010, Madhya Pradesh, India

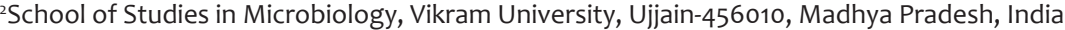

${ }^{3}$ Govt. Madhav Science College, Vikram University, Ujjain-456010, Madhya Pradesh, India

Received: July 24, 2020 Revised: February 13, 2021 Accepted: March 17, 2021 Published: March 29, 2021

*Corresponding Author: Rakesh Purbiya

E-mail: rakeshpurbiya25@gmail. com

\section{ABSTRACT}

The aim of this study was to find a suitable treatment combination that would effectively induce polyploidy in Coriander. In this study, colchicine concentrations and treatment durations were examined for improving the induction of polyploidy. The combinations of three colchicine concentrations such as $0.1 \%, 0.2 \%$ and $0.3 \%$ for 3 hrs per day for two to three days were tested in coriander. Three tetraploids were obtained in a $0.2 \%$ colchicine treated population. The treatment of colchicine (cotton swab method) seedling with $0.2 \%$ for 3 days was suitable for induction of chromosome doubling. The control plant showed eleven bivalents $(2 n=2 x=22)$ and the polyploid plant showed twenty two bivalents $(2 n=4 x=44)$ at diakinesis/metaphase-I in most of the PMCs. Anaphase-I distribution of chromosomes was normal (11:11) in control and in tetraploids distribution of chromosomes was (22:22) at each pole. In contrast with the normal plants, those treated by colchicine treatment often showed changes in height and width, in the thickness of branches, in size, shape, the texture of leaves, flowers, size of fruits and seed set.

KEYWORDS: Colchicine, Coriandrum sativum L., Polyploidy, Meiosis

\section{INTRODUCTION}

Coriandrum sativum L. $(2 n=22)$ is an annual herb that belongs to the family Apiaceae (Umbelliferae) is one of the most important cultivated (spice) crops in the world as well as India. Coriander is an aromatic plant, generally grown in winter. All the parts of the plant are edible but the fresh leaves and the dried seeds are most commonly used in cooking. It is an aromatic herb mainly used as a spice for adding taste and flavor to different food materials. The traditional uses of the coriander plants based on the primary products (fruits and the green herb) are medicinal and culinary (Bhati, 1988). The fruits are considered carminative, diuretic, tonic, stomachic, and antibilious. The essential oils of the fruits are possessing antibacterial and antioxidant activity (Bhandari \& Gupta, 1991). Apiaceae is the $16^{\text {th }}$ largest family of flowering plants containing about 200 genera and probably 2900 species; the family is cosmopolitan distributed worldwide except for Antarctica (Bentham, \& Hooker, 1883). As per the Angiosperm Phylogeny Group system (APG) IV (2016) the family Apiaceae contains about 434 genera and probably 3,700 species. Polyploidy (having four completes sets of chromosomes) is relatively common in plants. By some estimates, as many as $70 \%$ of all angiosperms are natural polyploids (Masterson, 1994). A diploid plant can become polyploid due to disruption in mitosis or meiosis. It can and does occur in nature, but is also induced by using chemicals like colchicine. Colchicine is a chemical, has been used since 1937 in plant breeding work to produce changes in plants by doubling the number of chromosomes in cells, a condition referred to as polyploidy. The increased number of chromosomes usually brings about an increase in the size of the affected cells and various degrees of changes in their functions. A number of reports indicate that besides quantitative changes in plants resulting from polyploidy there also have been changes of qualitative character. These may be in color intensity of leaves and flowers; in fragrance of leaves, flowers, or other plant parts; and in content of oils, starches, sugars, and vitamins. Fundamentally these changes that are ordinarily considered qualitative are mostly, if not entirely, changes of quantitative nature, since they result from either an increase or a decrease of the various products naturally present in the plants. Many workers have worked out the effects of colchicine on different plant species such as; Cosmos sulphureus (Verma et al., 2011b), Chrysanthemum carinatum (Verma et al., 2017), Phlox drummondii (Verma et al., 2018) and Rhoeo discolor (Verma et al., 201la).

\section{MATERIALS AND METHODS}

Dry and healthy seeds of coriander used for this study, were sown in pots. Young seedlings were selected for colchicine treatment.

Copyright: (C) The authors. This article is open access and licensed under the terms of the Creative Commons Attribution License (http://creativecommons.org/licenses/by/4.0/) which permits unrestricted, use, distribution and reproduction in any medium, or format for any purpose, even commercially provided the work is properly cited. Attribution — You must give appropriate credit, provide a link to the license, and indicate if changes were made. 
Small cotton swabs soaked in aqueous colchicine solution $(0.1 \%, 0.2 \%$ and $0.3 \%)$ were placed over apical meristem and solution added in drops at regular intervals for 3 days, with 3 hrs duration each day. Twenty seedlings each were treated with $0.1 \%$, twenty treated $0.2 \%$ and $0.3 \%$ colchicine. For meiotic analysis, young flower buds were fixed in 1: 3 (acetic acid: absolute alcohol) mixture for $24 \mathrm{~h}$. The anthers of appropriate size were squashed in $2 \%$ iron-acetocarmine. The plant height was measured from the base of the plant to the tip of flag leaf. The size of the stomata and pollen grains were also compared in controls and colhitetraploids. Plants' height was measured on the $90^{\text {th }}$ day (fully maturation) of germination. Standard deviation was computed.

\section{RESULTS}

Survival: In general, the survival of seedlings decreased when the concentration of colchicine was increased (Table 1). A major reduction in survival percentage was observed at the higher doses $(0.3 \%)$ of colchicine.

Success of polyploids: Following the seedling treatment method ( $0.2 \%$ for 3 hrs), three polyploids were produced. Successful results of polyploidy were obtained only $25 \%$ in $0.2 \%$ colchicine treatment (Table 1).

Plant height: The number of primary branches gets decreased according to dose dependent manner. The higher doses had shown negative influence as compared to control in which the mean value was recorded to $38 \mathrm{~cm}$ was measured in tetraploid and control group was $57.6 \mathrm{~cm}$. The number of primary branches showed a reduction in mean value as compared to control ones (Table 2).

Umbel/plant: Umbel with mostly 3-7 primary branches, schizocarp sub globose and marginal flowers of inflorescence with conspicuously petals. The maximum variation in number of

Table 1: Polyploid induction in Coriandrum sativum by colchicine treatment

\begin{tabular}{cccccc}
\hline S. No. & $\begin{array}{c}\text { Colchicine } \\
\text { concentration } \\
(\%)\end{array}$ & $\begin{array}{c}\text { No. of } \\
\text { seedlings }\end{array}$ & $\begin{array}{c}\text { No. of } \\
\text { survived } \\
\text { plants }\end{array}$ & $\begin{array}{c}\% \text { of } \\
\text { survived } \\
\text { plants }\end{array}$ & $\begin{array}{c}\% \text { of } \\
\text { obtained } \\
\text { polyploids }\end{array}$ \\
\hline 1 & Control & 10 & 10 & 100 & -- \\
2 & $0.1 \%$ & 20 & 14 & 70 & -- \\
3 & $0.2 \%$ & 20 & 12 & 60 & $25 \%$ \\
4 & $0.3 \%$ & 20 & 06 & 30 & -- \\
\hline
\end{tabular}

Table 2: Comparison of morphological characters in diploid (2x) and induced colchitetraploid $(4 \mathrm{x})$

\begin{tabular}{lcc}
\hline Characters & $\begin{array}{c}\text { Diploid } \\
\text { Mean } \pm \text { SD }\end{array}$ & $\begin{array}{c}\text { Tetraploid } \\
\text { Mean } \pm \text { SD }\end{array}$ \\
\hline Plant height $(\mathrm{cm})$ & $57.6 \pm 3.50$ & $38 \pm 2.16$ \\
Total no. of umbel/plant & $35.66 \pm 3.29$ & $15 \pm 3.77$ \\
Pollen fertility & $100 \%$ & $44 \%$ \\
Pollen shape & Dumbel shape & Triangle shape \\
No. of umblets/umbel & $244 \pm 19.79$ & $52 \pm 17.20$ \\
Seed weight (20 seeds) & $0.31 \mathrm{gms}$ & $0.67 \mathrm{gms}$ \\
\hline
\end{tabular}

umbel/plant was recorded at $0.3 \%$ colchicine concentration, followed by the mean value (15) for $0.2 \%$ colchicine concentration for $3 \mathrm{~h}$. The number of umblets per umbel was also decreased in tetraploids the mean value of umblets was 52 (Table 2).

Seed weight (20 seeds): The size of seed increased in the tetraploid plant $(0.2 \%$ colchicine treated) and weight of twenty seeds were measured in the tetraploid plant was $0.67 \mathrm{gms}$ as compare to control 0.3lgms (Table 2).

Pollen fertility and pollen shape: In the diploids, pollen fertility was $100 \%$. In all the induced polyploids, the pollen fertility was less than $50 \%$ (Table 2). The pollen grains of the polyploids were triangular, tetra angular and penta angular was observed whereas the pollen grains of diploid were dumbel in shape. In some cases, more than 4 microspores of unequal sizes were formed in a tetrad.

To observe the effect of colchicine on chromosomes, meiotic analysis was done from the anthers of control and colchicine treated plants.

\section{Meiosis in Control (diploids)}

The PMCs analyzed at diakinesis/metaphase-I had 11 bivalents $(2 n=22)$ (Figure 1A). Anaphase -I had a normal distribution of chromosomes (11:11) (Figure 1B). Telophase-I, metaphase-II, anaphase-II and telophase-II were also observed. The subsequent course of meiosis was normal, resulting in $100 \%$ of pollen fertility and good seed set.

\section{Meiosis in Colchicine Induced Tetraploids}

The cytology was observed in most of the induced polyploids as can be seen from Table 1 and Figure l(D-L). Different types of chromosomal associations were observed during meiotic analysis in colchiploids. PMC's showed 22II $(2 n=44)$ in tetraploid plants (Figure 1D). The anaphase I and II stages showed chromosome distributions (Figsurel, F\&H), bridge and laggards (Figs.l F\&I) and telophase II with 22 chromosomes on each pole (Figure 1J). Multi-polar telophase II was also observed in cells of the induced tetraploids.

The colhitetraploid plants showed rod shaped chromosome at diakinesis metaphase I, metaphase II, anaphase II with laggards, telophase II with bridges, telophase II with disturbed polarity, tetrad and pollen grains. Bridge and fragments at anaphase-I and telophaseII (FigurelF \& I) in meiotic division. At anaphase/telophase-I and II, more than 100 PMCs analyzed in the plant were found to have various patterns of chromosomes due to colchicine effect.

\section{DISCUSSION}

In the present investigation, three polyploid plants were obtained. The combinations of three colchicine concentrations such as $0.1 \%, 0.2 \%$ and $0.3 \%$ for 3 hrs were applied to the seedlings. The treatment of colchicine (cotton swab method) seedling with $0.2 \%$ 


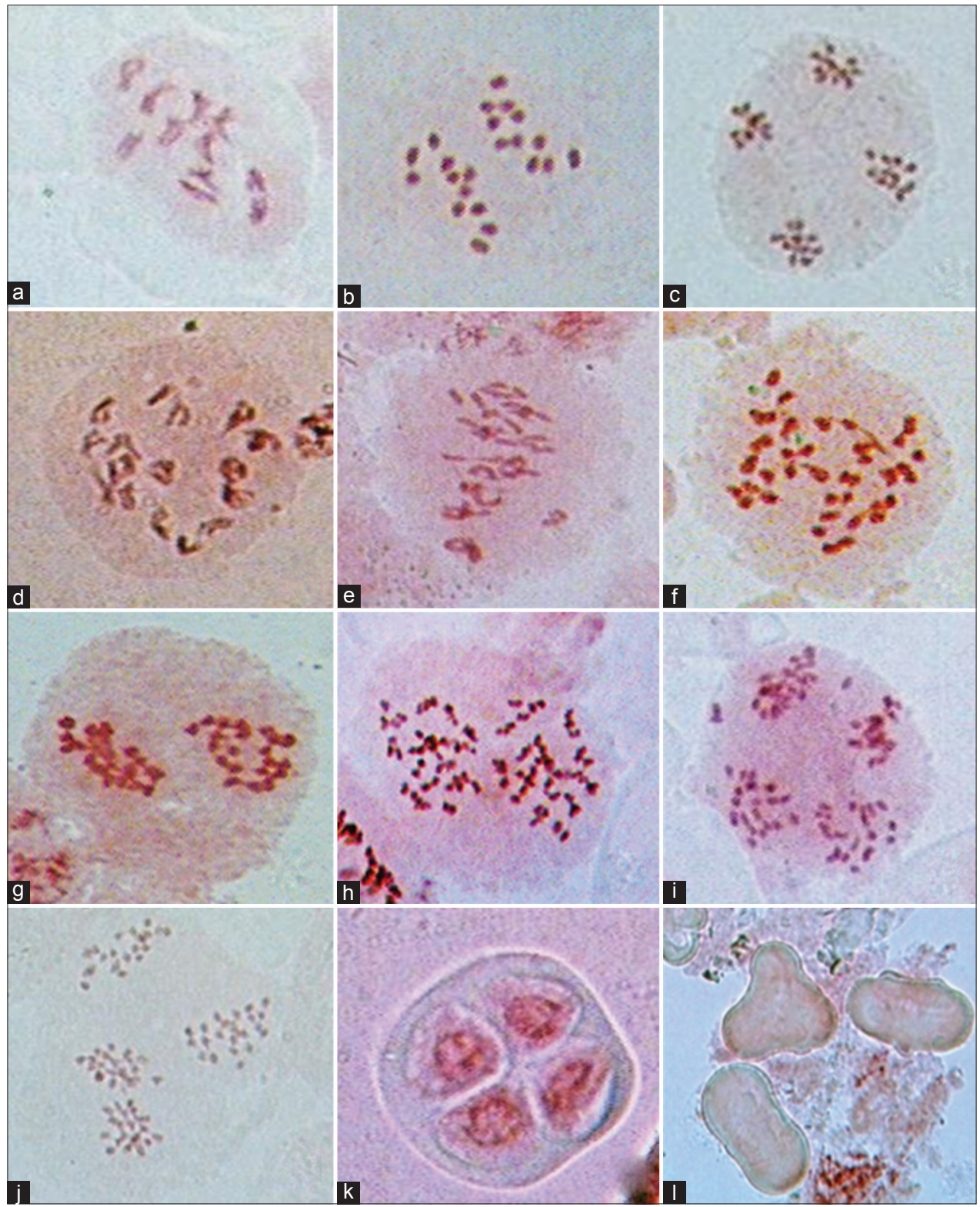

Figure 1: $(a-c)$ Meiosis in control $(2 x)$ a. Diakinesis with 11II $(2 n=22)$ b. Normal anaphase with 11:11 segregation c. Telophase-II (11 chromosome distributions at each pole) D-L) Meiosis in colchicine induced tetraploid (4x) d. Diakinesis with 22II (2n=44) e. Metaphase-I f. Anaphase-I, 22:22 segregation with bridge g. Telophase-I h. Prometaphase-II i. Anaphase-II with laggards j. Telophase-II (22 chromosome distributions at each pole) k. Tetrad I Pollen grains

for 3 hrs for 3 days was suitable for induction of chromosome doubling. Morphological variations were observed in all concentrations and duration of colchicine treatment. Tetraploid plants had distinct morphological features such as short plant height, slow and stunted growth, the bigger size of leaves, short stems and small number of umbels as compared to diploids. The length of the stomata, the breadth of the guard cells and the area, of the epidermal cells were almost doubled in tetraploids as compared to the diploids. Stomatal length and width, and the bigger fruits size in comparison to diploids were observed.

The large seed size in comparison to diploids, as in characteristic of tetraploids, the time taken for the seeds to mature is more than that required by diploids. Seed setting has been found to be very few, obviously due to meiotic irregularities resulting in the case of the tetraploids. Many treated plants showed some disorders in the growth and changes of leaf shape, many plants did not survive and necrotized in early growth stages because of the colchicine treatment. The colhitetraploids were confirmed by the growth rate, morphological characters, comparing the size of stomata and pollen grains as well as by cytological analysis. One general aspect of polyploids is that cell size is increased, presumably because there are more chromosomes in the nucleus. Often this increase in cell size is correlated with an overall increase in the size of an organism. 
In this study, tetraploids of coriander had shown some superior morphological characteristics than the diploids, such as larger, thicker leaves and greater fruit size. Successful induction of colhitetraploids has been reported by many workers in different plant species such as; Vicia faba (Joshi \& Verma, 2004) Phlox drummondii (Verma et al., 2011b) and Cosmos sulphureus (Verma et al., 2017). The grain yield and seed size are among the most important yield contributing factors in chickpeas and in this context the performance of tetraploids is encouraging (Sohoo et al., 1970).

The result of this study control plant showed eleven bivalents $(2 n=2 x=22)$ and the tetraploid plant showed 22 bivalents $(2 n=4 x=44)$ at diakinesis/metaphase-I in most of the PMCs. Anaphase-I distribution of chromosomes was normal (11:11) in control and in polyploids distribution of chromosomes was (22:22) at each pole. Polyploidy has played an important role in plant breeding as a valuable method for inducing variation and producing superior plants. Artificially induced polyploid method has been used to improve fruit size, yields, break self-incompatible system, restore fertility, and improves resistance to diseases and pests (Agrawal et al., 1990; Bhati, 1988).

Polyploidy is also assumed to have played an important role in speciation of plants. Polyploidy can occur using similar genetic material, as in autopolyploidy or using the genetic material from different species, as in allopolyploidy. The resulting polyploids can be more vigorous and display unique characteristics, contributing to the formation of new species.

\section{REFERENCES}

Agrawal, S., Sharma, R. K., \& Bhatt, B. N. (1990). Quality evaluation in coriander. Indian Cocoa, Arecanut and Spices Journal, 13, 137-138.

Angiosperm Phylogeny Group (APG) IV. (2016). An update of the Angiosperm Phylogeny Group classification for the orders and families of flowering plants: APG IV. Botanical Journal of the Linnean Society, 181, 1-20. https://doi.org/10.1111/boj.12385

Bentham, G., \& Hooker, J. D. (1883). Genera Plantarum. s.I.: Vol. 3 (2). Williams \& Norgate, 3, 477-1215.

Bhandari, M.M., \& Gupta, A. (1991). Variation and association analysis in coriander. Euphytica, 58, 1-4. https://doi.org/10.1007/BF00035333

Bhati, D. S. (1988). Effect of leaf plucking on growth, yield and economics of coriander varieties under semi-arid conditions. Indian Journal of Agronomy, 33, 242-244.

Joshi, P., \& Verma, R. C. (2004). High frequency production of colchicines induced autotetraploids in Faba bean (Vicia faba). Cytologia, 69, 141 147. https://doi.org/10.1508/cytologia.69.141

Masterson, J. (1994). Stomatal size in fossile plants: Evidence for polyploidy in majority of angiosperms. Science, 264, 421-423. https://doi. org/10.1126/science.264.5157.421

Sohoo, M. S., Athwal, D. S., \& Chandra, S. (1970). Colchicine Induced Polyploidy in Chickpeas (Cicer arietinum L.). Theoretical and Applied Genetics, 40, 63-168. https://doi.org/10.1007/BF00282697

Verma, R. C., Vyas, P., \& Raina, S. N. (2011a). The effect of colchicine on meiosis in the Rhoeo discolors stabile complex translocation heterozygote. Genome, 35, 611-613. https://doi.org/10.1139/ g92-091

Verma, R. C., Ahirwar, R., \& Das, P. (2011 b). Induction of polyploidy in Phlox drummondii by colchicine. Journal of Cytology and Genetics, 12, 1-5.

Verma, R. C., Dass, P., Shaikh, N., \& Khah, M. A. (2017). Cytogenetic investigations in colchicine induced tetraploid of Cosmos sulphureus (Asteraceae). Chromosome Botany, 12, 41-45. https:// doi.org/10.3199/iscb.12.41

Verma, R. C., Purbiya, R., \& Solanki, R. (2018). Effect of colchicine on meiosis of Chrysanthemum carinatum Schousb (Asteraceae) Chromosome Botany, 12, 91-94. https://doi.org/10.3199/iscb.12.91 